\title{
ESTRATÉGIA EDUCATIVA COM ENFOQUE NOS HÁBITOS ALIMENTARES DE CRIANÇAS: ALIMENTOS REGIONAIS
}

\author{
Mariana Cavalcante Martins¹, Lorena Barbosa Ximenes², Cíntia Freitas Casimiro³, Vanessa Gomes Silveiraª, Mirna \\ Albuquerque Frota ${ }^{5}$
}

\begin{abstract}
RESUMO: Estudo exploratório qualitativo com objetivo de desenvolver estratégia educativa sobre hábitos alimentares no período de alimentação complementar e utilização dos alimentos regionais em um Programa Saúde da Família em Maranguape - Ceará, Brasil. Os dados foram coletados através de entrevista semiestruturada e roda de conversa com 13 mães de crianças na faixa etária menor que seis meses que estavam em alimentação complementar. Os resultados foram analisados a partir das técnicas de análise temática de Bardin, emergindo as categorias: Necessidade biológica da criança; Alimentação e suas particularidades; e Inovando a alimentação com alimentos regionais. Promover saúde de crianças em alimentação complementar por meio da utilização dos alimentos regionais é uma temática que deve ser disseminada, em especial, no grupo de famílias que sofre com a desigualdade com intuito de contribuir na redução do impacto das desigualdades.
\end{abstract}

PALAVRAS-CHAVE: Suplementação alimentar; Promoção da saúde; Saúde da criança.

\section{EDUCATIONAL STRATEGY FOCUSING IN CHILDREN'S FEEDING'S HABIT: REGIONAL FOOD}

ABSTRACT: The research aimed to develop educational strategies on diet during the complementary feeding and use of regional food. Exploratory qualitative study developed in a Family Health Program in Maranguape - Ceará - Brasil. Data were collected through a semi-structured interview with 13 mothers of children aged less than six months that were enrolled to receive complementary feeding. The results were analyzed through Bardin's thematic analysis, and the emerged categories were: biological needs of the child, Feeding; and Innovating feeding with regional food. Therefore, promoting health of children in supplementary feeding through the use of regional food is a subject that should be disseminated, especially in the group of families that suffer with inequality in terms of social injustice.

KEYWORDS: Supplementary feeding; Health promotion; Child health.

\section{ESTRATEGIA EDUCATIVA CON ENFOQUE EN LOS HÁBITOS ALIMENTARES DE LOS NIÑOS: ALIMENTOS REGIONALES}

RESUMEN: Estudio exploratorio cualitativo con objetivo de desarrollar la estrategia educativa sobre hábitos alimentares en el periodo de alimentación complementaria y utilización de los alimentos regionales en un Programa de Salud de la Familia en Maranguape - Ceará, Brasil. Los datos fueron recolectados a través de una entrevista semiestructurada y rodada de conversación con 13 madres de niños de faja etaria menor que seis meses que se encontraban en alimentación complementaria. Los resultados fueron analizados a partir de las técnicas de análisis temático de Bardin, surgiendo las categorías: Necesidad biológica del niño, Alimentación y sus peculiaridades; e Innovando la alimentación con alimentos regionales. Promover salud de los niños en la alimentación complementaria mediante la utilización de los alimentos regionales es un tema que debe ser difundido, especialmente, en el grupo de familias que sufre con la desigualdad con el intuito de contribuir en la reducción del impacto de las desigualdades.

PALABRAS CLAVE: Alimentación suplementaria; Promoción de la salud; Salud del niño.

${ }^{1}$ Enfermeira. Discente do Curso de Doutorado em Enfermagem da Universidade Federal do Ceará-UFC. Bolsista da CAPES.

${ }^{2}$ Doutora em Enfermagem. Docente Adjunta III do Departamento de Enfermagem da UFC. Coordenadora do Programa de PósGraduação em Enfermagem da UFC.

${ }^{3}$ Discente do Curso de Graduação em Enfermagem da Universidade de Fortaleza-UNIFOR.

${ }^{4}$ Nutricionista. Mestranda em Saúde Coletiva da UNIFOR.

${ }^{5}$ Enfermeira. Doutora em Enfermagem. Docente Adjunta do Curso de Graduação em Enfermagem e do Mestrado em Saúde Coletiva da UNIFOR.

Autor correspondente:

Mariana Cavalcante Martins

Rua Capitão Américo Menezes, 387 - 60710-130 - Fortaleza-CE

Recebido: 23/06/09

E-mail: marianaenfermagem@hotmail.com

Aprovado: 30/09/09 


\section{INTRODUÇÃO}

A alimentação da criança desde o nascimento até os dois primeiros anos tem repercussões ao longo de toda a vida do indivíduo, sendo o aleitamento materno essencial para o crescimento e o desenvolvimento adequados. O leite materno, isoladamente, é capaz de nutrir as crianças nos primeiros seis meses de vida, porém, a partir desse período, deve ser complementado em decorrência das necessidades nutricionais. Para o Ministério da Saúde ${ }^{(1)}$, o aleitamento materno exclusivo é quando a criança recebe somente leite materno, diretamente da mama ou extraído, e nenhum outro líquido ou sólido, com exceção de gotas ou xaropes de vitaminas, minerais e/ou medicamentos.

Assim, o período de introdução da alimentação complementar deve ocorrer a partir dos seis meses, sendo etapa crítica que, com frequência, conduz à má nutrição e à enfermidades quando a criança não recebe dieta satisfatória; é algo a envolver complexos fatores sociais, econômicos e culturais que interferem no estado nutricional da criança. A adoção de práticas alimentares balanceadas nos primeiros anos de vida é relevante, pois esse é o período em que os hábitos alimentares são estabelecidos e continuarão na adolescência e na idade adulta ${ }^{(2)}$.

Em 2003, a edição da Política Nacional de Alimentação e Nutrição-PNAN, tinha como principal finalidade

contribuir com os debates sobre a luta contra a fome e a pobreza e para a construção de uma agenda política com a finalidade de prevenir a obesidade e demais doenças crônicas não transmissíveis no Brasil, bem como se constituir na contribuição concreta do setor Saúde para a Política de Segurança Alimentar e Nutricional(3:7).

Portanto, a política em prol da melhoria da situação nutricional da população existe, logo se deve dar mais ênfase para essa estratégia, tendo como respaldo as ações voltadas à melhoria da nutrição e, consequentemente, às condições de vida.

Assim, as ações de combate à pobreza no Nordeste devem considerar a importância das parcelas de renda rural, com ênfase na renda não agrícola como alternativa para reduzir o número de famílias rurais que estão abaixo da linha de pobreza e em condições de indigência ${ }^{(4-5)}$.

Em vista deste contexto, evidencia-se a ideia de que grande parte das comunidades da zona rural tem um ou dois alimentos básicos principais, isto é, o alimento com menor custo e de fácil acesso, sendo a base para preparar as primeiras refeições, a alimentação complementar, podendo fornecer a maioria dos carboidratos e frequentemente traz outros nutrientes necessários para o crescimento e desenvolvimento satisfatório da criança.

A não-utilização dos alimentos regionais de alto valor nutritivo pode suceder em decorrência de tabus, por influência cultural e/ou mau uso destes, sendo fator significativo que poderá repercutir na alimentação de muitas crianças, pois esses nutrimentos, se utilizados para prevenir carências nutricionais, influenciariam no quadro da desnutrição infantil.

A Educação em Saúde é uma ferramenta em que predomina como saber dominante a responsabilização das pessoas pela diminuição dos agravos à saúde. A Educação Popular pode ser utilizada como instrumento auxiliar na inclusão de novas práticas por profissionais e serviços de saúde. É notório o fato de que, cada vez mais, se buscam formas de atender às necessidades dos usuários por meio de prática educativa em saúde, em função da relevância assumida pelas experiências de promoção da saúde ${ }^{(6)}$.

O estudo emergiu da necessidade de alertar as mães sobre questões básicas, anteriormente desconhecidas, indispensáveis para complementar as atividades diárias desenvolvidas e promover a saúde da criança. Portanto têm-se como objetivo: desenvolver estratégia educativa com enfoque nos hábitos alimentares no período de alimentação complementar e utilização dos alimentos regionais.

\section{METODOLOGIA}

Realizou-se estudo exploratório qualitativo, pois se baseia na premissa de que os conhecimentos sobre os indivíduos são possíveis com a descrição da experiência humana vivenciada como é definida pelos próprios agentes, caracterizado por abordagem aprofundada em relação com o social, sendo forma inacabada da objetivação do saber, a subjetividade ${ }^{(7-8)}$.

O estudo foi realizado no Programa Saúde da Família-PSFESF, situado no Distrito de Sapupara localizado na zona rural do Município de Maranguape, região metropolitana, aproximadamente a 30 quilômetros de Fortaleza-CE. Participaram 13 mães tendo como critério de inclusão mães de crianças com idade menor ou igual a seis meses, que estavam no período de alimentação complementar. 
A idade das mães variou de 18 a 40 anos, sendo três adolescentes. Houve predomínio de mulheres em união consensual, nove. Destas, seis tinham um filho, quatro mães com dois, uma três, outra cinco e uma com nove filhos. No que se refere ao nível de instrução, mães com ensino fundamental incompleto apresentaram maior índice, uma exercia atividades fora de casa e as demais tinham ocupação do lar. Foi constatado que a maioria das mães (nove) sobreviviam com renda mensal menor que um salário mínimo, sendo quase a totalidade proveniente do programa do governo Bolsa Família e de rendas incertas do companheiro, destacando que uma das informantes não tinha renda, usufruindo, assim, da aposentadoria da avó da criança e outras duas mães tinham renda de dois salários mínimos.

Para a coleta dos dados, utilizou-se a entrevista semiestruturada, contendo dados de identificação dos informantes e características socioeconômicas; em seguida a roda de conversa, com duração de uma hora, durante quatro dias, abordando temas com questões roteiros: Saúde da Criança - Higiene, Alimentação Complementar, Alimentos Regionais. A fim de promover descrição fidedigna das falas, os discursos foram gravados, sendo previamente autorizadas pelas participantes.

Ressalta-se que os temas discutidos nas rodas de conversas foram guiados pelo manual do Ministério da Saúde, Guia Alimentar para Crianças Menores de Dois Anos e o livro Alimentos Regionais Brasileiros ${ }^{(1,9)}$.

Para análise dos dados, foi empregada a técnica de análise de conteúdo de $\operatorname{Bardin}^{(10)}$, seguindo as etapas: a pré-análise ou organização do material; a exploração desse material por meio da sua classificação e codificação ou categorização; e a interpretação dos resultados.

Os aspectos éticos estiveram presentes no decorrer da pesquisa, baseado na Resolução n¹96/96 do Conselho Nacional de Saúde ${ }^{(11)}$, incluindo a abordagem dos princípios da Bioética, de modo que as 13 mães participantes foram identificadas com nomes fictícios tais como: M1, M2 (...), M13, com intuito de preservar o anonimato. O estudo foi submetido ao Comitê de Ética em Pesquisa da Universidade de Fortaleza-UNIFOR, tendo sido aprovado sob o Parecer de N. 028/2007.

\section{RESULTADOS E DISCUSSÃO}

A transcendência da análise fez emergir as categorias: Necessidades biológica da criança; Alimentação e particularidades; Inovando a alimentação com alimentos regionais.

\section{Necessidades biológicas da criança}

A partir do questionamento: A criança sabe distinguir o doce do amargo, antes de 1 ano? As mães ficaram inquietas e evidenciaram o conhecimento da criança em distinguir sabores:

Lógico que sabe, por que não, a gente não sabe, por que a criança é diferente (M2).

A minha filha sabe porque quando coloco coisa doce na boca dela ela adora (M6).

O Manual do Ministério da Saúde ${ }^{(12: 21)}$ descreve que "a tendência do adulto é introduzir o açúcar por considerar o alimento da criança aguado", em razão da criança desconhecer o sabor adocicado e, portanto, não apresentar parâmetros para rejeitar o alimento. Dessa forma, percebeu-se a contextualização nos relatos das mães:

Eu nunca ouvi falar nisso, já me mandaram colocar açúcar no leite para a criança tomar todo, legal vivendo e aprendendo (M9).

Sabe-se que a criança quando ingere grande quantidade de açúcar não está sendo beneficiada, pois o componente presente no açúcar é calorias 18\%, baseada na tabela do INAN ${ }^{(13)}$, a qual era demonstrada para que houvesse melhor visualização e assimilação do que estava sendo informado.

Em continuidade, surgiu o segundo questionamento: Quantas vezes a criança deve beber água por dia? Partiu-se do princípio que as mães selecionadas têm crianças no período de alimentação complementar, no qual a ingestão de água é recomendada quando necessário e após as dietas.

Eu dou sempre 3 vezes por dia, de manhã, à tarde e à noite (M3).

Eu dou quando ela está com sede (M11).

Eu não sei se é certo, pois não fui orientada sobre a água, mais dou de manhã e de noite, duas vezes (M13). 
As mães demonstraram não ter certeza da informação, referindo a falta da orientação, de modo que a água deve ser oferecida à criança após as refeições ou quando estiver com sede, pois pode prevenir a desidratação e melhorar o funcionamento renal e digestivo da criança.

Dentro das orientações propostas nos manuais do MS, destaca-se que a partir da introdução dos alimentos complementares, deve-se acrescentar a água tratada, filtrada ou fervida na dieta da criança, nos intervalos das refeições ${ }^{(12,14)}$.

Sabe-se que a limpeza da cavidade oral das crianças é fundamental para prevenir inflamações por acúmulo de sujidades, emergindo o questionamento: A higiene da boca da criança deve ser feita? As mães ficaram em silêncio, com expressão facial de dúvida, rompido quando foi relatado:

Eu ouvi falar que a gente tem que passar algodão com água na gengiva, de vez em quando, mas eu não faço por que não vejo necessidade, ele é tão pequeno (M5).

Ai! Tem isso ainda, eu nunca tinha escutado falar, e prá que temos que limpar a gengiva? (M2).

Apesar do conhecimento materno em higienizar a cavidade oral da criança, a finalidade de tal ação é desconhecida, fato que pode ser decorrente do processo de orientação, didática verticalizada no momento das consultas. Ressalta-se que a limpeza ocorre por meio de remoção de resíduos de leite ou alimentos acumulados sobre a língua, próximo às bochechas e no canto da boca, com gaze, pano limpo ou algodão, de forma leve, para não remover as imunoglobulinas presentes na boca que protegem a criança ${ }^{(15)}$. Logo, o responsável pelo bebê é o agente mediador, pois quanto mais cedo se inicia a higiene bucal, a probabilidade de a criança apresentar lesões de cárie é reduzida ${ }^{(16)}$.

A implementação de ações preventivas e educativas em saúde, envolvendo além dos pais, familiares e filhos, profissionais comprometidos com a educação problematizadora, enfoca a adoção de hábitos de higiene regular e saudável, proporciona uma condição de saúde bem como o estabelecimento dos costumes adquiridos quando criança à vida adulta ${ }^{(17)}$.

\section{Alimentação e suas particularidades}

Essa categoria emergiu diante de peculiaridades inerentes à alimentação infantil, no qual se julga relevante a percepção materna. O uso do liquidificador é um hábito frequente como auxílio no preparo da alimentação da criança, sendo esta uma prática errônea. Assim, fez-se o questionamento: Quando deve ser utilizado o liquidificador para preparar alimentação da criança? Detectou-se que as sopas oferecidas às crianças eram trituradas no liquidificador:

Eu uso sempre, para fazer as sopinhas e suco (M3, M6, M8).

Eu só não uso mais por que não tenho, mais é mais rápido e peço emprestado, para fazer tudo (M2).

O liquidificador não é indicado no preparo das refeições da criança, pois reduz a consistência, mistura sabores e prejudica a saúde, devido aos malefícios associados. Os alimentos terão apresentação pastosa, ao serem amassados com garfo, não existindo a possibilidade de passar na peneira, uma vez que a criança está aprendendo a distinguir a consistência, sabores e cores dos novos alimentos ${ }^{(18)}$. Além do que, os alimentos liquidificados não estimulam o ato da mastigação.

Diante dos relatos, as mães acreditam que o alimento líquido é melhor para a criança, pois não têm dentes para mastigar, justificando que o ato da deglutição é facilitado. Logo, sabe-se que as mães apreendem interpretações sobre como cuidar do filho a partir da realidade que vivencia, sofrendo muitas vezes influências, repletas de tabus e crenças. No entanto, diante deste fato, o posicionamento correto dos profissionais da saúde nas orientações, tendo o cuidado em aliar o saber cultural com o científico, não negligenciando o contexto no qual a mãe esta inserida, contribui em uma melhor aceitação e inserção das informações.

A partir de uma reflexão sobre as influências exercidas nas mães em relação as orientações fornecidas na Unidade de Saúde e o poder de efetividade, emergiu a seguinte questão: $\mathrm{O}$ que devemos evitar na alimentação da criança?

Xilitos [salgadinhos industrializados] do chão (M2).

Não pode comer bagulho, bala, doce, xilito, refrigerante (M6).

Nem todo tipo de alimento que consumo o bebê pode comer, pois o organismo dele não digere bem, como xilito, biscoito, bombom, dizem que o miojo ${ }^{\circledR}$ 
faz mal, mas eu dou (M11).

Detectou-se que as mães possuem conhecimento de alguns alimentos que não podem ser oferecidos nessa fase da vida, contudo desconhecem os malefícios, uma vez que faltaram argumentos que justificassem a não utilização desses alimentos:

[...] sei não, só sei que não pode, pois o povo fala por aí (M3).

Assim, é necessário repensar sobre a forma como está acontecendo as orientações para com as mães e a estratégia desenvolvida durante a abordagem das temáticas de interesse materno direcionadas à saúde infantil.

Diante dessa perspectiva, Freire acrescenta que existem duas concepções da educação: bancária e problematizadora. Na concepção bancária, o educador é o que sabe e o educando, é o que não sabe, sendo passivo, tornando-se depósito de informações, meros objetos. Na vertente problematizadora, os homens caminham para a libertação, na qual o educador e educando aprendem juntos, por meio de construção do saber, visando à transformação da realidade enquanto ação política e prática da liberdade ${ }^{(19)}$.

No momento em que as mães finalizaram o discurso, houve explanação de maneira clara e sucinta sobre a utilização do macarrão instantâneo tão utilizado e contra-indicado, por possuir substâncias no tempero que contêm corantes e aditivos químicos.

Sempre me diziam que era ruim dá miojo ${ }^{\circledR}$, mas não me dizia por que, e eu continuava dando, é prático e rápido e ele gosta (M11).

O macarrão instantâneo apresenta em média $380 \mathrm{kcal}$, semelhante ao tradicional, mas é composto por alto teor de gordura, que equivale a $21 \%$ da recomendação diária, e alto teor de sódio, cerca de $90 \%$ da recomendação diária para um adulto ${ }^{(20)}$. Portanto, existem dados que comprovam a contraindicação da utilização de macarrão instantâneo em adultos demonstrando ser, consequentemente, desvantajoso para crianças.

Para as crianças em alimentação complementar, deve ser evitado o uso de alimentos industrializados, enlatados, embutidos e conservantes artificiais, por apresentarem a mucosa gástrica sensível, comprometendo a digestão e a absorção dos nutrientes, além do baixo teor nutricional ${ }^{(14)}$.

Baseado nos relatos finalizou-se a etapa de questionamentos: Devemos oferecer a alimentação da criança com auxílio de mamadeira, copinho e colher? Sabe-se do predomínio na utilização da mamadeira para auxiliar na dieta da criança, entretanto, argumentaram que o correto seria oferecer no copinho, no qual o relato torna-se diferente da prática.

Sei que tem que dá no copinho, mais demora muito, ele enrola é melhor na mamadeira, desce mais rápido (M1).

Tudo que ele toma é na mamadeira, não toma nada no copinho, derrama tudo (M7).

A prática da utilização da mamadeira ainda prevalece depois de tantas evidências que o uso deste instrumento causa malefícios para a saúde da criança, como prejudica a arcada dentária e proporciona ainda o desmame, sendo difícil a limpeza eficaz.

Os manuais do $\mathrm{MS}^{(14,18)}$ descrevem que a higiene de quem prepara e oferece as mamadeiras é o passo inicial para evitar possível contaminação do alimento e, consequentemente, da criança, devido à dificuldade de limpeza e adequação da higienização. Quando se opta por utilizar a mamadeira, a limpeza ocorre em sete passos, fato que demonstra as vantagens em utilizar o copo ${ }^{(18)}$. Além disso, o bebê, ao sugar na mama após ter sido alimentado com mamadeira ou ter sido exposto a um bico artificial, adota padrão de sucção diferente do assumido com os bicos artificiais, o que leva à dificuldade do lactante em conseguir amamentar-se com êxito.

\section{Inovando a alimentação com alimentos regionais}

Foi necessário inovar estratégias sobre o hábito alimentar característico da região, os alimentos regionais, uma vez que são subutilizados. $\mathrm{O}$ alimento regional ${ }^{(9)}$ é compreendido por vários tipos de alimentos e não apenas as frutas, pois é composto por hortaliças, tubérculos, leguminosas, dentre outras, característicos de determinadas regiões. No presente estudo, a percepção materna em relação aos alimentos regionais limitou-se as frutas características da região e incertezas sobre tal alimentação:

E difícil falar de alimentos regionais, pois a gente nunca ouviu falar disso (M1). 
Eu acho que alimento regional é aquele que tem na nossa região, mais próximo da gente, como banana, mamão, caju, é bem barato esses alimentos, na época deles [...] (M6).

Detectou-se a existência da subutilização dos alimentos regionais em virtude da falta de conhecimento, o que caracterizou a necessidade em propagar os benefícios dos alimentos regionais na alimentação de crianças. Assim, tomando como base as frutas relatadas nos discursos, poderiam ser desenvolvidas receitas com a banana, colocada dentro da farofa para substituir a carne; o caju, do qual se pode fazer o suco enquanto a fibra poderia preparar a “carne” básica de caju, dentre outros.

Após a discussão, houve explanação e distribuição de receitas utilizando alimentos regionais, referindo seus respectivos valores nutritivos, sendo estas retiradas do livro do $\mathrm{MS}^{(9)}$ : Alimentos regionais Brasileiros e do portal do SESI ${ }^{(21)}$. Assim, à medida que se evidenciava novas formas de alimentações, as mães se surpreendiam com a variedade de preparo, por se apresentar de forma acessível, econômica e rápida, que até então eram desconhecidos:

Como eu queria ter sabido disso antes, teria economizado tanto dinheiro, mas agora eu já sei (M5).

No último dia de encontro foi oferecido às mães e às crianças suco da folha da siriguela e várias mães e filhos experimentaram. Essa estratégia surgiu para fundamentar a prática com a teoria explanada, com intuito de reduzir o tabu existente. As crianças demonstraram boa aceitação e isso proporcionou surpresa para as mães, como no relato antes de oferecer o suco para a criança:

Não tem nem perigo, dele tomar isso, ele não vai gostar (M13).

A prática de Educação em Saúde realizada em um grupo de mães interessadas na saúde do filho é fundamental, pois por meio dessa estratégia se desenvolve a consciência crítica, viabilizando pontos positivos como também negativos e dificuldades dentro de um contexto social para realização de determinada prática $^{(22)}$.

Assim, o momento de informação é complexo, uma vez que tem que desenvolver o processo de consciência crítica sobre a temática; de modo que é necessário compreender o aprendizado do receptor, refletido sobre a assistência à saúde prestada ${ }^{(23)}$. No entanto, as mães julgaram relevantes as informações evidenciadas durante o processo de intervenção educativa pois, de acordo com os discursos, foram abordados pontos que não haviam sido debatidos durante o acompanhamento da criança na US.

Para tanto, pode-se concluir sobre a necessidade da implantação de estratégias educativas para com familiares de criança no período de alimentação complementar, com a finalidade de promover à saúde da coletividade.

\section{CONSIDERAÇÕES FINAIS}

A temática apontou que as mães não foram orientadas sobre a existência desses alimentos e suas diversas formas de preparo, sendo acentuada a presença das frutas, utilizadas na maioria para fazer sucos. Diante desta percepção, foi necessário divulgar receitas contendo os alimentos regionais como primordial, proporcionando nova forma de alimentação para a criança, bem como obter a satisfação materna por meio de processos educativos acerca de alimentação saudável e de baixo custo.

É notável, inclusive, a relevância da inserção dos alimentos regionais no cardápio de crianças inseridas em uma parcela da sociedade que vive na zona rural, bem como o surgimento de uma reconscientização para com as mães, evidenciando uma alimentação adequada e saudável.

Ressalta-se o papel estratégico de relações estabelecidas no cotidiano das Unidades de Saúde para o processo de mudança social e "empoderamento" das pessoas. Assim, além de propor estratégias, o Ministério da Saúde deve investir na formação dos gestores e trabalhadores sob a lógica da integralidade das ações de saúde, aptos a compreender a realidade de vida da população, criar vínculos e trabalhar em equipe, priorizando a promoção da saúde de maneira dialógica, crítica e reflexiva.

Assim, para as equipes de saúde, este momento é oportuno a fim de despertarem a criatividade e sensibilidade, proporcionando a melhoria da qualidade de vida da comunidade na qual se encontram, com o trabalho voltado além da cura e reabilitação do indivíduo, na prevenção de doenças por intermédio da educação em saúde desenvolvida com as famílias da comunidade. 


\section{REFERÊNCIAS}

1. Ministério da Saúde (BR). Organização Pan-Americana de Saúde. Guia alimentar para crianças menores de 2 anos. Serie A. Normas e manuais técnicos ${ }^{\circ} 107$. Brasília (DF): Ministério da Saúde; 2002.

2. Simon VGN, Souza JMP, Souza SB de. Introdução de alimentos complementares e sua relação com variáveis demográficas e socioeconômicas, em crianças no primeiro ano de vida, nascidas em Hospital Universitário no município de São Paulo. Rev Bras Epidemiol. 2003; 6(1): 29-38.

3. Ministério da Saúde (BR). Política Nacional de Alimentação e Nutrição. $2^{a}$ ed. Brasília: Ministério da Saúde; 2003.

4. Carvalho CMB. Alimentação da criança nos três primeiros anos de vida: manual para auxiliares de enfermagem, agentes de saúde e seus supervisores. Fortaleza: Secretaria Estadual do Ceará; 1994.

5. Neder HDN, Silva JLM. Pobreza e distribuição de renda em áreas rurais: uma abordagem de inferência. Rev Economia Sociologia Rural. 2004; 42(3):469-86.

6. Frota MA, Albuquerque CM de, Linard AG. Educação popular em saúde no cuidado à criança desnutrida. Texto Contexto Enferm. 2007; 16(2):246-53.

7. Minayo MCSP. O desafio do conhecimento: pesquisa qualitativa em saúde. São Paulo: HUCITEC; 2001.

8. Polit FD, Hungler PB. Fundamentos de pesquisa em enfermagem. $3^{\mathrm{a}}$ ed. Porto Alegre: Artes Médicas Sul; 2004.

9. Ministério da Saúde (BR). Alimentos regionais Brasileiros. Brasília: Ministério da Saúde; 2002.

10. Bardin L. Análise de conteúdo. Lisboa: Edições 70; 2000.

11. Ministério da Saúde (BR). Conselho Nacional de Saúde. Comissão Nacional de Ética em Pesquisa - CONEP. Resolução n. 196/96. Dispõe sobre pesquisa envolvendo seres humanos. Brasília: Ministério da Saúde; 1996.

12. Ministério da Saúde (BR). Guia prático de preparo de alimentos para crianças menores de 12 meses que não podem ser amamentadas. Brasília: Ministério da Saúde; 2005.

13. Instituto Nacional de Alimentação e Nutrição - INAN. Gráficos de comparação de valores nutritivos. Brasília: Ministério da Saúde; 1996.
14. Ministério da Saúde (BR). Organização Pan-Americana de Saúde. Dez passos para uma alimentação saudável: guia alimentar para crianças menores de 2 anos. Brasília: Ministério da Saúde; 2002.

15. Ministério da Saúde (BR). Política Nacional de Promoção da Saúde. Brasília: Ministério da Saúde; 2002.

16. Volpato LER, Figueiredo AF de. Estudo da clientela do Programa de Atendimento Odontológico Precoce em um serviço público do município de Cuiabá, Mato Grosso. Rev Bras Saude Mater Infant. 2005; 5(1):45-52.

17. Cruz AAG, Gadelha CGF, Cavalcanti AL, Medeiros PFV de. Percepção Materna Sobre a Higiene Bucal de Bebês: Um Estudo no Hospital Alcides Carneiro, Campina Grande-PB. Pesq Bras Odontoped Clin Integr. 2004; 4(3):185-9.

18. Ministério da Saúde (BR). Departamento de atenção básica. Saúde da família no Brasil: uma análise de indicadores selecionados: 1998-2004. Brasília: Ministério da Saúde; 2006.

19. Freire P. Pedagogia do oprimido. $46^{\mathrm{a}}$ ed. São Paulo: Paz e Terra; 2007.

20. Dant. Coordenação de vigilância em saúde. Almanaque DANT. Publicação da Gerência de Comunicação e Educação. São Paulo: COVISA; 2004.

21. SESI. Programa SESI Cozinha Brasil ensina como aproveitar integralmente o caju. [acesso em 2007 Ago 29]. Disponível: http://projetocajusesi2007.html

22. Frota MA, Aderaldo NNS, Silveira VG, Rolim KMCR, Martins MC. O reflexo da orientação na prática do aleitamento materno. Cogitare Enferm. 2008 Jul/ Set;13(3):403-9.

23. Deslandes SF, Ayres JRCM. Humanização e cuidado em saúde. Cienc Saúde Col. 2005;10(3):510. 